\title{
Two new primitive ant genera from the late Eocene European ambers
}

Gennady M. Dlussky and Alexander G. Radchenko

Acta Palaeontologica Polonica 54 (3), 2009: 435-441 doi: http://dx.doi.org/10.4202/app.2008.0092

Two extinct genera of ants from the late Eocene (ca. $40 \mathrm{Ma}$ ), Protomyrmica gen. nov. and Plesiomyrmex gen. nov. (family Formicidae, subfamily Myrmicinae), are described based on single specimens (males), from Baltic and Bitterfeld (also called Saxonian) ambers respectively; both genera belong to the tribe Myrmicini. In gross morphology they are similar to modern Myrmica but have a series of apomorphies combined with characters that are plesiomorphic not only in the tribe Myrmicini, but also in the subfamily Myrmicinae. The most significant plesiomorphies concern the antennal structure and wing venation of both genera. The antennal scape is short and the funiculus is filiform, having no apical club. Moreover, the antennae of Protomyrmica are "sphecoid" with the length of the funicular segments gradually decreasing towards the apex (i.e., the longest is basal, starting from the second, and the shortest is apical); this type of structure is basal for the family Formicidae as a whole. Although we consider the wing venation of Protomyrmica to represent the prototype of wings in the subfamily Myrmicinae, it has an apomorphy absent in the modern Myrmicini genera - the antennae are inserted into the head well behind the posterior margin of the clypeus. Plesiomyrmex also has a peculiar apomorphy not found in any other genus of Myrmicinae: the antennae are inserted into toruli located on short sub-vertical tube-like or cup-like structures that protrude distinctly above the head surface. As a result, we do not consider either of the newly described genera to be the direct ancestors of modern Myrmicini; nevertheless, the presence of very ancient plesiomorphies may indicate their antiquity, and thus the latest estimated time for the origin of the tribe Myrmicini should be at least the early Eocene.

Key words: Insecta, Hymenoptera, Formicidae, Myrmicinae, evolution, Baltic Amber, Bitterfeld Amber, Eocene.

Gennady Dlussky [dlusskye@mail.ru], Moscow State University, Biological Faculty \{in Russian?\}, Vorob'evy gory, 119899, Moskva, Russia; Alexander Radchenko [agradchenko@hotmail.com], Muzeum i Instytut Zoologii, Polska Akademia Nauk, ul. Wilcza, 64, PL-00-679, Warszawa, Polska 
This is an open-access article distributed under the terms of the Creative Commons

Attribution License (for details please see creativecommons.org), which permits unrestricted use, distribution, and reproduction in any medium, provided the original author and source are credited.

FoF 